\title{
Corticosteroids in Treatment of Chronic Asthma
}

\author{
SADIE D. WALSH,* M.B., M.R.C.P.ED.; I. W. B. GRANT,† M.B., F.R.C.P.ED.
}

Brit. med. F., 1966, 2, 796-802

Chronic or continuous bronchial asthma is a disabling and potentially dangerous disorder, for which the only effective treatment in the majority of cases is the administration of corticosteroids. There was at first some reluctance to use these agents on a long-term basis, mainly because of a discouraging report from the Medical Research Council (1956), but in the past nine years many well-documented studies have testified to the value of this form of treatment (Phear, Ball, and Page, 1960 ; Bruce Pearson, Baylis, and Smellie, 1961 ; Livingstone and Davies, 1961 ; Rees and Williams, 1962). There are indeed few respiratory physicians who do not now believe that it is indispensable to the management of severe chronic asthma.

In the Respiratory Diseases Unit of the Northern General Hospital, Edinburgh, corticosteroids have been used in the treatment of chronic asthma since 1953. Until 1958 we adopted the then orthodox policy of selecting patients for long-term treatment on purely clinical criteria. Patients with severe asthma which did not respond adequately to bronchodilator drugs were first given a seven-day course of corticosteroid. If the asthma was of the chronic or continuous type there was inevitably a recurrence of symptoms a few days or a few weeks after treatment was stopped. Another course of corticosteroid was then given, and the cycle of improvement and deterioration was usually repeated. After a time, often as a result of pressure from the patient or from the general practitioner, and seldom as a deliberate decision, a daily maintenance dose of corticosteroid was sanctioned by the consultant, and this form of long-term treatment, once started, could seldom be stopped, even for a day. This was clearly an unsatisfactory way to use a potentially dangerous drug, and in 1958 one of us (I. W. B. G.), working in collaboration with Dr. A. R. Somner, decided to experiment with methods of administering corticosteroids intermittently.

It had been observed that in most cases of chronic asthma the improvement produced by a short course of corticosteroid persisted for a few days after trcatment was stopped, and there appeared to be fairly good grounds for assuming that, in some patients at least, symptoms could be controlled by the administration of corticosteroids for two or three consecutive days every week, or for a longer period every fortnight or every month. It seemed possible that if a regimen of this type could be used the various metabolic disturbances caused by the short courses of corticosteroid would subside or perhaps even be entirely reversed during the periods between treatment. Some support for this hypothesis has since been obtained from the work of Harter, Reddy, and Thorn (1963), who showed that the metabolic effects of a single dose of prednisone given every 48 hours were substantially corrected during the second period of 24 hours after each dose was given. The results of our preliminary experience with intermittent corticosteroid therapy in chronic asthma were reported six years ago (Somner, Rogan, and Grant, 1960). Groups of severe but otherwise unselected chronic asthmatics were treated with $20 \mathrm{mg}$. of

* Registrar in General Medicine, Western General Hospital, Edinburgh t Consultant Physician, Respiratory Diseases Unit, Northern Genera Hospital, Edinburgh.

Reprints from University Department of Respiratory Diseases, City Hospital, Greenbank Drive, Edinburgh 10. prednisolone per day on (a) two consecutive days per week, (b) three consecutive days per week, (c) eight consecutive days per month, or $\left(d^{\prime}\right)$ six consecutive days per fortnight. For purposes of comparison a separate group was given treatment every day with 10 to $15 \mathrm{mg}$. of prednisolone. In general, intermittent treatment was less effective than continuous (daily) treatment, but most of the patients to whom it was given every week on either two or three days obtained, to quote from the summary of the original paper, " a useful degree of symptomatic improvement." Those in whom it was given less frequently, but for longer periods, fared less well, and these methods of administration were thought to be of no value. It was felt that the results with intermittent treatment could be improved, at least in some cases, if the patients were selected with greater discrimination, and if care was taken to ensure that each of them received a treatment regimen which suited their individual requirements. The methods used to implement these conditions are fully described below.

From 1958 onwards every patient with chronic asthma referred to this unit was assessed according to a standard procedure, the objectives of which were as follows: (1) to determine whether the disability caused by chronic asthma was sufficiently severe and/or continuous to warrant long-term treatment with corticosteroids ; (2) to determine, in those patients requiring long-term treatment, whether it should be given intermittently or continuously; and (3) to determine the appropriate regimen and dosage.

Between 1958 and 1963 long-term corticosteroid therapy was instituted on these indications in 236 patients with chronic asthma. This paper reports the results of treatment in these cases and in 37 cases treated prior to 1958 who were given long-term corticosteroid therapy on purely clinical indications and who all received continuous (daily) treatment.

\section{Patients Submitted to Analysis}

The series included every patient admitted with chronic asthma who received long-term treatment with corticosteroids between 1953 and 31 December 1963. These patients were all reviewed between January and March 1965, by which time every one of them had been receiving corticosteroids for at least a year.

Table I shows the composition of the series according to age and sex. There was a slight predominance of males in children

\begin{tabular}{|c|c|c|c|c|c|}
\hline & & & Males & Females & Total \\
\hline $\begin{array}{l}\text { Adults } \\
\text { Children under } 15\end{array}$ & $\begin{array}{l}\cdots \\
\cdots\end{array}$ & . & $\begin{array}{l}93 \\
17 \\
\end{array}$ & $\begin{array}{r}152 \\
. \quad 11 \\
\end{array}$ & $\begin{array}{r}245 \\
28\end{array}$ \\
\hline Total, & . & .. & 110 & 163 & 273 \\
\hline
\end{tabular}

under 15 years of age, and a 1.16:1 predominance of females in the adult group. Fig. 1 shows that the number of females increased progressively with each decade until the fifth. The number of males was much smaller in the second, third, and fourth decades, but rose steeply in the fifth decade to exceed the number of females. Although the numbers of patients over the age of 60 were very much smaller than those in the 
peak fifth decade, the series included no fewer than 36 patients (11 male and 25 female) in this age group. No patient was indeed denied long-term corticosteroid therapy solely on account of age.

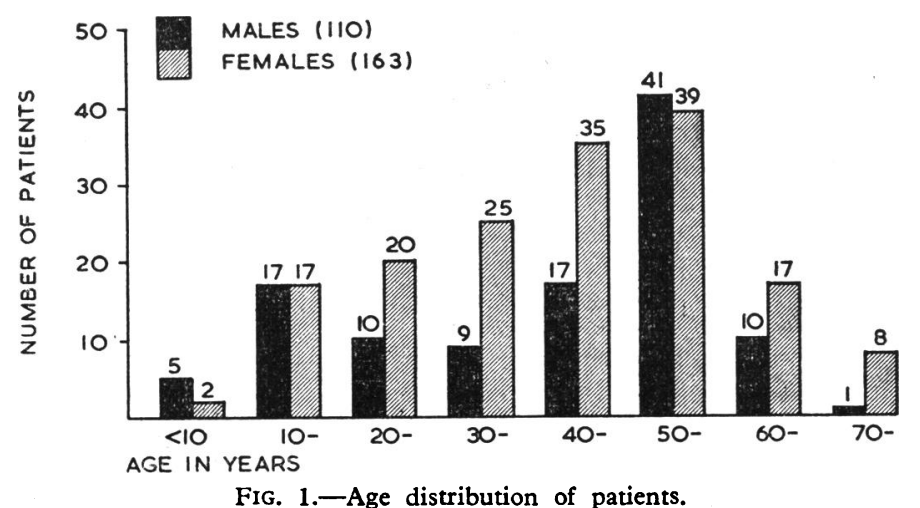

The ages of children ranged from 7 to 14 years, but few under the age of 10 were in fact referred for assessment. The children in the series thus cannot be regarded as forming a representative cross-section of the asthmatic population in this age group, and for that reason are described in a separate section at the end of this report.

\section{Selection of Patients for Long-term Corticosteroid Therapy and Determination of Appropriate Regimen}

The selection of patients with chronic asthma for long-term corticosteroid therapy involved three distinct procedures.

\section{(A) Clinical Assessment of Severity of Symptoms and a Detailed Inquiry whether Measures other than Corticosteroids had been Used to Full Advantage}

In most cases the respiratory disability was very severe and had persisted for weeks, months, or even years, unrelieved by bronchodilator drugs, of which a great variety had usually been tried. If there was any doubt whether the symptoms were severe enough to warrant corticosteroids, or if it appeared that the effect of bronchodilator drugs had not been fully exploited, the next step in the investigation was deferred for at least a month. During this period the patient was seen weekly, or more often if necessary, and his response to bronchodilators assessed by regular estimations of forced expiratory volume. In some of these cases no indication for corticosteroid therapy emerged ; in others the need for it was clearly demonstrated.

\section{(B) Spirometric Assessment of Effect of a Corticosteroid Preparation on Airways Obstruction}

Before a patient was selected for long-term corticosteroid therapy it was thought essential to determine whether, and to what extent, the airways obstruction could be reversed by a seven-day course of treatment with a corticosteroid preparation. When this policy was first adopted in 1958 we did not know what relation, if any, existed between the short-term and longterm response to corticosteroids, but it seemed at the time reasonable to assume that those patients in whom the forced expiratory volume in one second (F.E.V.. $)$ increased by less than $30 \%$ after seven days of treatment were unlikely to benefit from long-term corticosteroid therapy. It became our standard practice to advise long-term treatment only for patients in

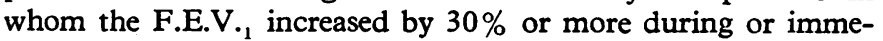
diately after the initial seven-day "assessment course." This course, as is shown below, was used not only to discover whether the asthma was responsive to corticosteroids but also to deter- mine the appropriate treatment regimen. The assessment was conducted as follows:

1. Whenever possible the patient was admitted to hospital in order to reduce to a minimum the effects of variations in temperature, weather, and atmospheric allergens on the F.E.V.

2. Initially the patient was given inert tablets (one tablet four times daily) identical in appearance and taste with 5-mg. prednisolone tablets. The F.E.V.1 was recorded between 9 and 10 a.m. each day, and as soon as a stable "baseline" of F.E.V. recordings had been established ( $\pm 100 \mathrm{ml}$. on three consecutive days) $5-\mathrm{mg}$. prednisolone tablets were substituted, without the patient's knowledge, for the inert tablets. This treatment was maintained for a period of seven days, during which daily recordings of F.E.V. were continued. The "percentage response" was calculated as follows:

Highest F.E.V., during treatment less highest of last three baseline F.E.V., recordings

Highest of last three baseline F.E.V., recordings $\times 100$

\section{(C) Determination of Appropriate Treatment Regimen}

If the patient showed a response of more than $30 \%$ to the seven-day course of prednisolone inert tablets were again substituted, and the F.E.V..$_{1}$ was then recorded twice daily (at approximately 9 a.m. and 9 p.m.) for the next four days. The object of this part of the procedure was to determine the length of remission (to the nearest 12-hour period) produced by the course of prednisolone. This information was then used as follows to select the treatment regimen appropriate to the particular patient (Fig. 2):

1. If the F.E.V. began to fall less than 24 hours after the last dose of prednisolone (Fig. 2 a), intermittent treatment was unlikely to be effective and continuous (daily) treatment was accepted as being necessary.

2. If the F.E.V. began to fall between 24 and 48 hours after the last dose of prednisolone (Fig. 2 b), intermittent treatment on alternate days was advised.

3. If the F.E.V. began to fall between 48 and 96 hours after the last dose of prednisolone (Fig. $2 \mathrm{c}$ ), intermittent treatment on two consecutive days in every four was advised.

4. If the F.E.V. was showing no tendency to fall more than 96 hours after the last dose of prednisolone (Fig. $2 \mathrm{~d}$ ), one of two

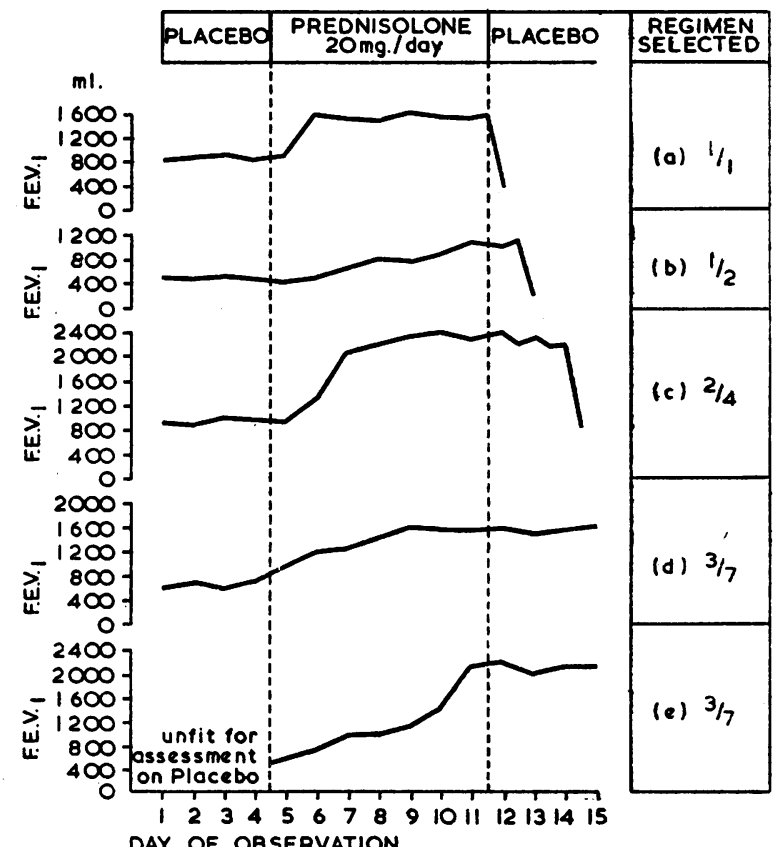

FIG. 2.-Assessment of response to prednisolone in five typical cases: (a) Patient requiring continuous (daily) treatment $(1 / 1)$. (b) Patient suitable for intermittent treatment on alternate days $(1 / 2)$. (c) Patient suitable for intermittent treatment on two consecutive days in every four $(2 / 4)$. (d) Patient suitable for intermittent treatment on three consecutive days per week $(3 / 7)$. (e) Patient unfit for initial period on placebo but accepted as suitable for intermittent treatment on three consecutive days per week $(3 / 7)$. 
courses was adopted: (a) If there had been a period of more than four weeks of continuous severe asthma immediately before the assessment, intermittent treatment on three consecutive days per week was started immediately. (b) If continuous severe asthma had lasted for less than four weeks before the assessment, long-term treatment was withheld pending a period of further observation at weekly intervals. If a major recurrence of asthma developed within the next month, intermittent treatment on three consecutive days per week was started.

This procedure could not always be followed in every detail. Some patients were in such severe respiratory distress when they were admitted to hospital that it would not have been safe to withhold treatment with corticosteroids in order to obtain " baseline" recordings of F.E.V. on inert tablets. The course we adopted in these cases (Fig. 2 e) was to give a large dose of prednisolone initially (up to $60 \mathrm{mg}$./day in a severe case), reduce it gradually to $20 \mathrm{mg}$./day as the symptoms subsided, and maintain this dose until the daily F.E.V. recordings reached a stable level. Inert tablets were then substituted and the assessment was continued according to the standard programme. If the F.E.V. fell after prednisolone was stopped this was usually taken to indicate that the asthma was responsive to corticosteroids, but a reversal of this trend following the reintroduction of prednisolone was deemed necessary for confirmation.

In some cases the serial F.E.V. recordings showed erratic variations which made it difficult or even impossible to assess the response to prednisolone. The F.E.V. might, for example, rise steadily for a few days and then fall sharply while prednisolone was still being given. This phenomenon appeared to be related in some instances to the development of respiratory infection, but in others no cause for it could be found. The policy we adopted in these cases was to repeat the assessment, if necessary, after the infection had been controlled by an antibiotic, and in most instances a more decisive result was obtained at the second attempt.

Another problem was that presented by those patients who did not respond to the standard dose $(20 \mathrm{mg} . /$ day $)$ of prednisolone but in whom there were indications from the history that the airways obstruction was at least partially reversible. The policy we adopted in these cases also was to repeat the assessment, but on the second occasion a higher initial dose (60-100 mg./day) of prednisolone was given. The dose was generally reduced to $20 \mathrm{mg}$./day for a few days before inert tablets were substituted, and the assessment was completed in the usual way. Such patients seldom proved to be suitable for intermittent treatment, and most of them required continuous treatment with a relatively high daily dose of prednisolone.

\section{Subsequent Management of Patients Receiving Long-term Treatment}

Prednisolone was used in almost every case, partly because we had no grounds for suspecting that it was less effective than any of the newer synthetic corticosteroids, and partly because the results of our observations would be less difficult to analyse if all patients were treated with the same drug.

The initial dosage schedules are shown in Table II. It can be seen that all patients on intermittent treatment initially received the same total dose of prednisolone (approximately $60 \mathrm{mg}$./week). The average dose received by patients on continuous (daily) treatment was slightly higher (71 mg./week).

Every patient was reviewed in a special asthma clinic four weeks after discharge from hospital and at regular intervals thereafter, the frequency of visits being governed by the patient's progress. At each visit the weight was recorded, the chest was examined clinically, the urine was tested for albumin and glucose, and the F.E.V. 1 was estimated. Arrangements were also made for annual radiological examination of the chest.

\section{Results of Treatment in 245 Adults}

\section{Distribution of Treatment Regimens (Table II)}

Sixty-five patients $(26 \%)$ received continuous (daily) treatment, while $180(74 \%)$ received some form of intermittent treatment regimen. The group receiving continuous treatment has been subdivided into series A (33 cases) and series B (32 cases). Series $\mathrm{A}$ includes those patients in whom treatment was started prior to 1958 without any preliminary assessment

\begin{tabular}{|c|c|c|c|c|c|}
\hline $\begin{array}{c}\text { Regimen } \\
\text { (Prednisolone) }\end{array}$ & $\begin{array}{c}\text { Abbrevia- } \\
\text { tion }\end{array}$ & $\begin{array}{l}\text { Daily } \\
\text { Dose }\end{array}$ & $\begin{array}{l}\text { Mean } \\
\text { Weekly } \\
\text { Dose }\end{array}$ & \multicolumn{2}{|c|}{ No. of Patients } \\
\hline 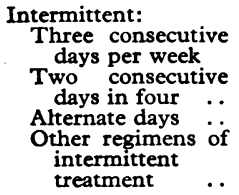 & $\begin{array}{r}3 / 7 \\
2 / 4 \\
1 / 2 \\
\text { Other }\end{array}$ & $\begin{array}{c}20 \mathrm{mg} . \\
17 \cdot 5 \mathrm{mg} . \\
, \\
\text { Variable }\end{array}$ & $\begin{array}{c}60 \mathrm{mg} . \\
61 \mathrm{mg} . \\
, \\
\text { Variable }\end{array}$ & $\begin{array}{l}94(38 \%) \\
44(18 \%) \\
30(12 \%) \\
12(5 \%)\end{array}$ & $180(74 \%)$ \\
\hline $\begin{array}{l}\text { Continuous: } \\
\text { Daily (no initial } \\
\text { assessment) } \quad . \\
\text { Daily (after initial } \\
\text { assessment) .. }\end{array}$ & $\begin{array}{c}1 / 1 \\
(\text { series A) } \\
1 / 1 \\
\text { (series B) }\end{array}$ & $10.1 \mathrm{mg}$. & $71 \mathrm{mg}$. & $\begin{array}{l}33(14 \%) \\
32(13 \%)\end{array}$ & $65(26 \%)$ \\
\hline
\end{tabular}

of their response to corticosteroids, and series $\mathrm{B}$ those patients treated from 1958 onwards in whom an elective decision to give continuous treatment was based on the standard initial assessment already described. In the group receiving intermittent treatment 94 were stabilized on a $3 / 7$ regimen, 44 on a $2 / 4$ regimen, 30 on a $1 / 2$ regimen, and 12 on regimens not conforming with the main categories.

\section{Duration of Treatment (Table III)}

With the exception of three patients who died or whose treatment was stopped within the first year all the 245 patients submitted to analysis had received corticosteroids for at least 12 months, and $61(25 \%)$ for over five years. In $41 \%$ of patients in all treatment groups it was possible to reduce the initial maintenance dose, often considerably, but complete with-

TABLE III. -Duration of Treatment (245 Adults)
\begin{tabular}{rr|r|r|r|r|r|r|r|r|r|r|r|r}
\hline Years: & $0-1$ & $1-$ & $2-$ & $3-$ & 4 & $5-$ & $6-$ & $7-$ & $8-$ & $9-$ & $10-$ & Total \\
\hline $\begin{array}{l}\text { Treatment } \\
\text { continuing }\end{array}$ & & - & 52 & 38 & 42 & 29 & 12 & 18 & 6 & 12 & 5 & 3 & 217 \\
Treatment stopped & 1 & 1 & 4 & 1 & 3 & 1 & 0 & 1 & 0 & 0 & 0 & 12 \\
Deaths .. &.. & 2 & 6 & 3 & 2 & 0 & 2 & 1 & 0 & 0 & 0 & 0 & 16
\end{tabular}

TABLE IV.-Reductions in Dosage in Relation to Treatment Regimens (245 Adults)

\begin{tabular}{|c|c|c|c|c|c|c|c|}
\hline \multirow[b]{2}{*}{$\begin{array}{c}\text { Regimen } \\
\text { (Prednisolone): }\end{array}$} & \multicolumn{4}{|c|}{ Intermittent } & \multicolumn{2}{|c|}{ Continuous } & \multirow[b]{2}{*}{ Total } \\
\hline & $3 / 7$ & $2 / 4$ & $1 / 2$ & Other & $\begin{array}{c}1 / 1 \\
\text { (series } \\
\text { A) }\end{array}$ & $\begin{array}{c}1 / 1 \\
\text { (series } \\
\text { B) }\end{array}$ & \\
\hline No. of patients & 94 & 44 & 30 & 12 & 33 & 32 & 245 \\
\hline $\begin{array}{l}\text { Mantenance } \\
\text { dose reduced }\end{array}$ & $\begin{array}{c}40 \\
(42 \%)\end{array}$ & $\begin{array}{c}17 \\
(39 \%)\end{array}$ & $(31 \%)$ & 0 & $\begin{array}{l}21 \\
(64 \%)\end{array}$ & $\begin{array}{c}14 \\
(44 \%)\end{array}$ & $\begin{array}{l}101 \\
(41 \%)\end{array}$ \\
\hline $\begin{array}{c}\text { Treatment } \\
\text { stopped: } \\
\text { Patients well }\end{array}$ & 4 & 2 & 0 & 4 & 2 & 0 & $\begin{array}{c}12 \\
(5 \%)\end{array}$ \\
\hline
\end{tabular}

drawal of corticosteroid therapy was possible in only $5 \%$. Table IV sets out the individual figures for each treatment group. The only group which shows a significant departure from the norm is the $1 / 1$ (series A) group, in which dosage reduction was achieved in $64 \%$. This higher figure may, however, merely reflect the longer duration of treatment in this group. 


\section{Response to Treatment}

The response to long-term treatment was classified as follows:

+3 : Symptoms of chronic asthma completely or almost completely relieved. No acute episodes. All F.E.V.1 recordings at or near post-assessment figure.

+2: Considerable improvement in symptoms of chronic asthma. Two or less acute episodes per year. Most F.E.V.1 recordings at or near post-assessment figure.

+1: Slight improvement in symptoms of chronic asthma. Three or more acute episodes per year. Few F.E.V.1 recordings at or near post-assessment figure.

0 : Symptoms of chronic asthma and number of acute episodes uninfluenced by treatment. No F.E.V.1 recordings at or near post-assessment figure.

Most of the patients who showed $a+3$ or $a+2$ response were able to return to regular employment, or in the case of married women to resume full household duties, although those with a +2 response usually had one or two periods of incapacity per year, each lasting for two to three weeks. The exceptions were those patients whose initial symptoms were not entirely due to reversible airways obstruction and who were left with a residual respiratory disability, presumably caused by emphysema, after the asthma had been effectively controlled. Patients in whom the response was classified at +1 or 0 were regarded as treatment failures, although many of those in the +1 response group claimed that the benefit they derived from the treatment enabled them to lead more active lives than hitherto. The reason for continuing treatment in those patients who showed no objective or subjective long-term response was the development of a curious phenomenon, which for lack of a better term will be described as "corticosteroid dependence." Attempts to withdraw treatment in these cases immediately provoked a complaint of increased dyspnoea. This was not associated with a reduction in F.E.V., and its cause is obscure. Some of these patients also experienced other symptoms, such as lassitude, mental depression, and arthralgia, when treatment was tentatively withdrawn or even when the dose was reduced. Corticosteroid dependence of this type apparently takes at least a month to develop, and can be avoided if treatment is not continued after the initial assessment has shown it to be of no value. In most of the cases in this series it had been induced before the patients were referred to hospital ; these patients had been given corticosteroids by their general practitioners for long periods before it was appreciated that the treatment was ineffective.

The response to treatment of the 245 adult patients in the various treatment groups is shown in Table $\mathrm{V}$. Of those who were found suitable for treatment on three consecutive days per week or on two consecutive days in four, approximately two-thirds obtained virtually complete relief of symptoms, while less than $10 \%$ failed to derive some benefit from the treatment. Less satisfactory results were obtained in patients who required treatment on alternate days, and in those who, after the initial assessment, were deemed to require continuous (daily) treatment (series B). A possible reason for the relative lack of success with these treatment regimens is that the patients were selfselected unstable asthmatics, in whom the therapeutic effect of corticosteroids persisted for only a short space of time after each dose or each series of doses was given. Those patients whose continuous (daily) treatment started before 1958 (series

TABLE V.-Response to Treatment in Relation to Regimen Employed

\begin{tabular}{|c|c|c|c|c|c|c|}
\hline \multirow[b]{2}{*}{$\begin{array}{c}\text { Regimen } \\
\text { (Prednisolone): }\end{array}$} & \multicolumn{4}{|c|}{ Intermittent } & \multicolumn{2}{|c|}{ Continuous } \\
\hline & $3 / 7$ & $2 / 4$ & $1 / 2$ & Other & $\begin{array}{c}1 / 1 \\
\text { (Series A) }\end{array}$ & $\begin{array}{c}1 / 1 \\
\text { (Series B) }\end{array}$ \\
\hline No. of patients .. & 94 & 44 & 30 & 12 & 33 & 32 \\
\hline Response $\left\{\begin{array}{rr}+3 & \ldots \\
+2 & \ldots \\
+1 & \ldots \\
0 & \ldots\end{array}\right.$ & $\begin{array}{r}63 \% \\
22 \% \\
11 \% \\
4 \%\end{array}$ & $\begin{array}{c}66 \% \\
27 \% \\
7 \% \\
0\end{array}$ & $\begin{array}{r}37 \% \\
47 \% \\
13 \% \\
3 \%\end{array}$ & $\begin{array}{l}25 \% \\
41 \% \\
17 \% \\
17 \%\end{array}$ & $\begin{array}{l}46 \% \\
24 \% \\
18 \% \\
12 \%\end{array}$ & $\begin{array}{r}28 \% \\
41 \% \\
25 \% \\
6 \%\end{array}$ \\
\hline
\end{tabular}

A) showed an intermediate grade of response, presumably because this group consisted of a mixture of patients who might have fallen into any of the other groups if their response to corticosteroids had been assessed by our present methods.

\section{Incidence of Side-effects (Table VI)}

The majority of patients developed moonface, which was of marked degree in $38 \%$ of those on continuous treatment but in only $12 \%$ of those on intermittent treatment. In a few cases other manifestations of hypercorticism, such as facial plethora, acne, striae, hirsutism, purpura, and hypertension, were also noted. Peripheral oedema, often severe enough to warrant treatment with a diuretic, also occurred more frequently in patients receiving continuous treatment. The incidence of fractures occurring either spontaneously or as a result of minor trauma was much higher in patients on continuous treatment $(15 \%)$ than in those on intermittent treatment $(1 \%)$. Wedge fractures, often multiple, of vertebral bodies and cough fractures of the ribs accounted for all but one of the incidents.

Table VI.-Side-effects in 245 Adult Patients

\begin{tabular}{|c|c|c|c|c|c|c|}
\hline & \multicolumn{3}{|c|}{$\begin{array}{c}\text { Continuous Treatment } \\
\text { (65 Patients) }\end{array}$} & \multicolumn{3}{|c|}{$\begin{array}{c}\text { Intermittent Treatment } \\
\text { (180 Patients) }\end{array}$} \\
\hline : & $\mathbf{M}$ & $\mathbf{F}$ & $\%$ & $\mathbf{M}$ & $\mathbf{F}$ & $\%$ \\
\hline $\begin{array}{l}\text { Marked hypercorticism } \\
\text { Oedema } \\
\text { Spontaneous fracture(s) } \\
\text { "New" peptic ulcer } \\
\text { Reactivation of known } \\
\text { peptic ulcer or dys- } \\
\text { pepsia without demon- } \\
\text { strable ulcer }\end{array}$ & $\begin{array}{r}15 \\
6 \\
9 \\
2\end{array}$ & $\begin{array}{r}10 \\
5 \\
1 \\
1\end{array}$ & $\begin{array}{l}38 \% \\
16 \% \\
15 \% \\
4.5 \%\end{array}$ & $\begin{array}{l}4 \\
1 \\
0 \\
3\end{array}$ & $\begin{array}{r}18 \\
11 \\
2 \\
1\end{array}$ & $\begin{array}{r}12 \% \\
6 \% \\
1 \% \\
2 \%\end{array}$ \\
\hline
\end{tabular}

The remaining patient sustained a subtrochanteric fracture of the left femur. Seven patients $(2.8 \%)$ developed peptic ulcers, three while on continuous treatment and four while on intermittent treatment. A much larger number of patients $(12 \%$ of the series) either had a recurrence of symptoms from a previously diagnosed peptic ulcer or developed ulcer-type dyspepsia for which no cause could be found on radiological examination. The incidence of proved and suspected peptic ulceration was not significantly different in the two treatment groups. No attempt was made in these cases to withdraw corticosteroids or to reduce the dose, even in two patients who developed haematemesis. Instead, enteric-coated prednisolone tablets were substituted for the ordinary tablets, and the patients were treated with bed rest, diet, and antacids. With these measures the symptoms usually subsided rapidly, and there were no major complications apart from the two incidents of haemorrhage already mentioned. Two patients, however, ultimately required gastrectomy.

Less common side-effects included diabetes mellitus ( 3 cases), corticosteroid myopathy ( 1 case), muscle cramps ( 7 cases), and pulmonary tuberculosis ( 1 case). One patient developed rheumatoid arthritis and three patients had recurrence of eczema or psoriasis when attempts were being made to withdraw corticosteroids. The number of patients in whom these uncommon side-effects occurred was too small to provide any impression of their relative frequency in the two treatment groups.

So far as we are aware, none of the patients in the series ever showed an inadequate pituitary-adrenal response to stress, although this could not be altogether excluded in the case of those who died suddenly at home. All patients were issued with "steroid cards," which drew attention to this hazard and indicated how it could be avoided. Supplementary treatment with cortisone acetate was given to all patients undergoing surgical procedures, minor as well as major, and to all pregnant women at the time of delivery. Eleven surgical operations (seven major and four minor) were performed, with no mor- 
tality. Eleven patients became pregnant-10 had uneventful normal deliveries and one required caesarean section. No maternal deaths occurred, but there were two stillbirths, one resulting from placenta praevia and the other caused by neonatal hypoxia.

\section{Relation of Regimen and Dosage to Incidence of Side-effects}

It has already been shown that some of the more common side-effects, such as moonface, peripheral oedema, and spontaneous fracture, were more frequently encountered in patients receiving continuous treatment than in those receiving intermittent treatment. There was, however, a slight difference between the mean annual dose in the two groups in that patients on continuous treatment received $3.7 \mathrm{~g}$. of prednisolone, while those on intermittent treatment received $3.15 \mathrm{~g}$. Although this represents a difference in the daily dose of prednisolone of only $1.5 \mathrm{mg}$., we had to consider the possibility that the increased incidence of side-effects in patients on continuous treatment might mainly affect those who received an annual dose well in excess of the norm. We therefore calculated the mean annual dose received by patients on continuous treatment who had developed fractures, and found it to be $4.34 \mathrm{~g}$. The corresponding figure for patients who did not develop fractures was $3.55 \mathrm{~g}$. These figures are equivalent to daily doses of 11.9 and $9.7 \mathrm{mg}$. respectively. The annual dose of prednisolone may thus have been more relevant to the production of fractures than the type of regimen by which it was given.

Nevertheless, fractures did occur in 3 of the 36 patients $(8.3 \%)$ who had received continuous treatment in a mean annual dose of $3.65 \mathrm{~g}$. or less (equivalent to a daily dose of $10 \mathrm{mg}$. or less). In contrast, 2 of the 180 patients $(1 \%)$ in the intermittenttreatment group sustained fractures, although this group had received only a slightly smaller mean annual dose of prednisolone $(3.15 \mathrm{~g}$.). The difference between the incidence of fractures in these two groups is more than twice the standard error, and is thus of statistical significance. The validity of the analysis is, however, open to question because the mean annual dose of prednisolone was not identical in the two groups. All patients on continuous treatment were given either anabolic steroids or calcium supplements in an effort to prevent osteoporosis, but in view of the number of fractures observed it seems unlikely that these measures were of any practical value.

In the series as a whole, those patients who sustained fractures were on average older ( 52.1 years) than those who did not (46.2 years), and males $(8.3 \%)$ were more prone to fractures than females $(2.4 \%)$. This would seem to indicate that the liability to corticosteroid fractures is influenced by age and sex, the hazard being greatest in elderly subjects, particularly males.

\section{Deaths (Table VII)}

Sixteen patients $(6 \%)$ died during the period of observation, seven from status asthmaticus and nine from other causes. In those patients who died from status asthmaticus the main reason for the fatal outcome seems to have been a failure to

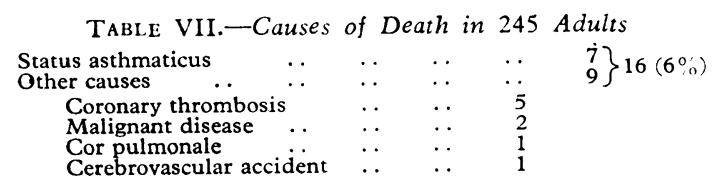

increase the dose of corticosteroid when acute symptoms supervened. As most of these patients died at home it was impossible to exclude the possibility that an inadequate pituitary-adrenal response to stress had contributed to the fatal outcome. The death rate was no higher in patients on intermittent treatment than in those on continuous treatment.

\section{Results of Treatment in 28 Children}

The ages of the 28 children ( 17 males and 11 females) treated ranged from 4 to 14 years. When the analysis was carried out 14 had been under treatment for one to three years, and the same number for longer periods. An analysis of the treatment regimens (Table VIII) showed that continuous (daily) treatment

\begin{tabular}{|c|c|c|c|}
\hline \multicolumn{2}{|c|}{ Regimen (Prednisolone) } & \multirow{2}{*}{$\begin{array}{c}\text { Adults } \\
94(38 \%) \\
44(18 \%) \\
30(12 \%) \\
12(5 \%) \\
65(27 \%)\end{array}$} & \multirow{2}{*}{$\begin{array}{c}\text { Children } \\
6(21 \%) \\
5(18 \%) \\
6(21 \%) \\
0 \\
11(40 \%)\end{array}$} \\
\hline Intermittent & $\begin{array}{c}3 / 7 \\
2 / 4 \\
1 / 2 \\
\text { Other } \\
1 / 1\end{array}$ & & \\
\hline \multicolumn{2}{|c|}{ Total } & 245 & 28 \\
\hline
\end{tabular}

was more frequently required in children (40\%) than in adults $(26 \%)$, and when an intermittent treatment regimen was used that in which corticosteroids were given on three consecutive days per week was less often effective in children than in adults. Provided a suitable regimen was used, however, the response to long-term treatment in children was no less satisfactory than that observed in adults (Table IX). Over two-

TABLE IX.-Comparison of Response to Treatment in Adults and

\begin{tabular}{|c|c|c|}
\hline Response & Adults (245) & Children (28) \\
\hline $\begin{array}{r}+3 \\
+2 \\
+1 \\
0\end{array}$ & $\begin{array}{r}52 \% \\
30 \% \\
13 \% \\
5 \%\end{array}$ & $\begin{array}{r}60 \% \\
32 \% \\
4 \% \\
4 \%\end{array}$ \\
\hline
\end{tabular}

thirds obtained virtually complete symptomatic relief, and only one child out of 28 failed to derive significant benefit from the treatment. In many the improvement was dramatic, and in some of the younger children a fairly severe degree of chest deformity resolved completely after the asthma was controlled.

The side-effects encountered in the children were marked hypercorticism in 15 , and bleeding peptic ulcer, pulmonary tuberculosis, diabetes mellitus, and spontaneous fracture in one each. In general, the children required a proportionately higher dose of corticosteroid than the adults, and they were in consequence more liable to develop stigmata of hypercorticism. Only two serious side-effects were, however, encounterednamely, haematemesis from an acute gastric erosion in one case and a spontaneous fracture of a lumbar vertebra in another. Fortunately, complete recovery ensued in both cases. There were no deaths among the children in the series.

It was possible to reduce the initial maintenance dose, often considerably, in $50 \%$ of cases, and in $5(18 \%)$ corticosteroid therapy was successfully withdrawn, a somewhat higher proportion than in the adult series (Table $\mathrm{X}$ ).

\begin{tabular}{l|c|c|c}
\multicolumn{3}{c}{ TABI.E X.-Reduction in Dosage } \\
\hline \\
$\begin{array}{l}\text { Maintenance dose reduced } \\
\text { Treatment stopped: patients well }\end{array}$ & $\cdots$ & $\begin{array}{c}101(41 \%) \\
12(5 \%)\end{array}$ & $\begin{array}{c}\text { Cdults }(245) \\
5\left(10^{\circ} \%\right)\end{array}$ \\
\hline
\end{tabular}

Because of fears expressed that corticosteroids retarded the growth of children, this problem was examined in some detail (Table XI). Before treatment was started the mean height of 27 children in whom records were complete was $2 \mathrm{~cm}$. less than that of comparable controls. After treatment was established 11 children increased in height at the normal rate, and six more rapidly than normal. In the remaining 10 , however, there was clear evidence of a retarded rate of growth, which was pronouncd in two cases. As in all these children the asthma was well controlled, it is difficult to escape the conclusion that corticosteroids were responsible for the growth retardation. 
TABLE XI.-Effect on Height and Weight of 27 Children

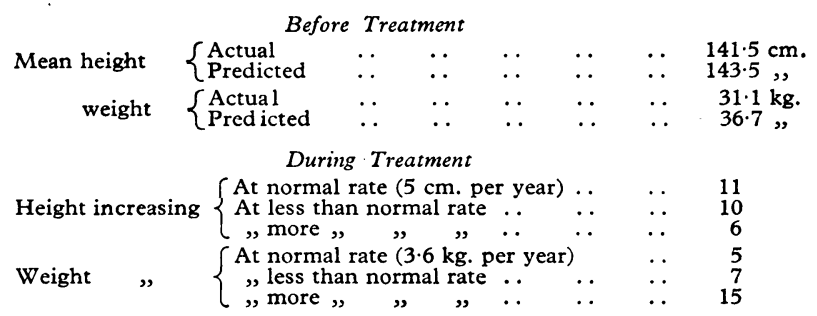

The weight of the children before and during treatment was also studied. The mean pretreatment weight was no less than $5.6 \mathrm{~kg}$. below that of comparable controls, but it subsequently increased rapidly, and more than $50 \%$ of the children eventually became overweight.

\section{Discussion}

When this investigation was started in 1958 it was hoped to show that intermittent treatment with corticosteroids in suitably selected cases was just as effective as the conventional type of continuous (daily) treatment, but less likely to produce serious side-effects. With the method of assessment described in this paper it has been possible to identify those patients who are likely to respond satisfactorily to long-term corticosteroid therapy, and to select for most of them regimens of intermittent treatment which in practice have proved to be subjectively and objectively effective. Furthermore, the initial assessment has also indicated which patients are unlikely to respond to longterm treatment with corticosteroids, and has thus spared them unnecessary exposure to a potentially dangerous drug.

Because the policy which governed the selection of cases and the planning of treatment regimens differed fairly radically from that adopted in other studies, it has not been possible to make any precise comparison of the results in this series with those reported previously. The 33 unselected patients who formed series $\mathrm{A}$ in the group receiving continuous (daily) treatment were, however, managed along similar lines to the large series studied by Rees and Williams (1962), and the results were virtually identical. There is no reason to believe that the indications for long-term treatment were any different in the remaining 212 patients than in the original series of 33 . Nevertheless, the process of selecting patients for the various treatment regimens produced a sharp distinction between the results obtained with intermittent treatment on three days in seven or two days in four, which were better than those in the unselected cases of series $A$, and those obtained with intermittent treatment on alternate days or with elective continuous treatment (series B), which were worse than those in the unselected cases of series A.

The probable reason for these differences is that patients in whom remissions of symptoms produced by prednisolone persist for two days or more after treatment is stopped have a type of asthma which is readily suppressed by corticosteroids. It is possible that the asthma in such cases could have been equally well controlled by a daily dose of prednisolone without exceeding the total weekly dose of $60 \mathrm{mg}$. used in our standard intermittent-treatment regimens. It could also be argued that the patients who received treatment on alternate days would have responded equally well, or possibly even better, to daily treatment, although they might have required a slightly higher dose than patients in the other two groups.

The whole concept of intermittent corticosteroid therapy could indeed be dismissed as a rather complicated way of separating patients into various grades of "corticosteroidresponsiveness" who merely required different daily doses of prednisolone to suppress their symptoms. To refute such an argument completely it would be necessary to conduct a largescale clinical investigation specifically designed to compare the two methods of treatment. The current study has, however, provided sufficient evidence to justify a more extensive trial of intermittent corticosteroid therapy. In support of this statement there is first the theoretical argument, based on the work of Harter et al. (1963), that the metabolic disturbances responsible for most of the side-effects produced by corticosteroids may to a large extent be nullified if treatment is given intermittently. Secondly, observations on a large series of patients in the present study have indicated that intermittent treatment in suitably selected cases suppresses the symptoms of chronic asthma at least as effectively as continuous (daily) treatment. Thirdly, it has been shown that serious side-effects are exceedingly uncommon among patients given intermittent treatment, even for periods of as long as five years.

It must be admitted that the higher incidence of side-effects observed in patients on continuous (daily) treatment may have been related in part to the higher annual dose of corticosteroid these patients received, and for that reason alone we cannot conclude that intermittent treatment is necessarily safer than continuous treatment. Nevertheless, we can reasonably claim that the policy we have pursued in regard to the use of intermittent corticosteroid therapy has yielded results which are certainly not inferior in terms of either therapeutic efficacy or safety to those obtained by workers who have favoured the conventional practice of daily administration. There is still ample scope for experimentation in the logistics of corticosteroid administration in chronic asthma, and it is hoped that this paper will stimulate further efforts to devise the best possible method for utilizing these dangerous but often miraculously effective drugs.

\section{Summary}

An account is given of the results of treatment with prednisolone, and of the side-effects encountered, in 273 patients with chronic asthma ( 245 adults and 28 children) in whom treatment had been maintained for periods of 1 to 10 years.

In $180(74 \%)$ of the 245 adult patients prednisolone was given intermittently $(20 \mathrm{mg}$./day on three consecutive days per week, $17.5 \mathrm{mg}$./day on two consecutive days in every four, or $\mathbf{1 7 . 5}$ mg. on alternate days); the remainder received continuous (daily) treatment with an average dose of $10.1 \mathrm{mg}$./day. In 212 patients the response to prednisolone was tested by serial estimations of forced expiratory volume (1 second) before they were accepted for long-term treatment, and the length of remission after withdrawal of prednisolone was used to determine the appropriate regimen in each case. In the remaining 33 patients, who started corticosteroid therapy prior to 1958 , no such preliminary assessment was undertaken, and they were all given continuous (daily) treatment.

The symptoms of asthma were almost completely relieved in two-thirds of those patients who were found suitable for treatment on three consecutive days per week or on two consecutive days in four, but in only one-third of those who required treatment on alternate days or every day. Those who received daily treatment without preliminary assessment showed a response midway between that observed in the first two categories. In the series as a whole $81 \%$ of patients obtained a useful degree of symptomatic improvement, and in only $5 \%$ was treatment totally ineffective. The maintenance dose of prednisolone was reduced, often considerably, in about $50 \%$ of cases, but it was possible to withdraw treatment completely in only $5 \%$.

The frequency of side-effects, such as marked hypercorticism, peripheral oedema, and spontaneous fracture, was lower in patients on regimens of intermittent treatment than in those receiving prednisolone daily. This may have been partly related to the slightly smaller mean annual dose of prednisolone received by patients on intermittent treatment, but significantly fewer incidents of spontaneous fracture occurred with inter- 
mittent treatment than with continuous (daily) treatment given in a comparable mean annual dose. The incidence of suspected and proved peptic ulceration was approximately the same in the two treatment groups. Sixteen patients $(6 \%)$ died, seven from status asthmaticus and nine from other causes. The deaths from status asthmaticus were probably due to failure to increase the dose of corticosteroid when acute symptoms supervened. The death rate was no higher in patients on intermittent treatment regimens than in those given corticosteroids every day.

The results in 28 children were similar to those obtained in the 245 adults, but the children required a proportionately higher dose of corticosteroid, and were in consequence more liable to develop the stigmata of hypercorticism. More serious side-effects were uncommon, and no deaths were recorded. Intermittent treatment was effective less of ten in children than in adults, but complete withdrawal of corticosteroids was achieved more often in children (18\%) than in adults $(5 \%)$. Although growth had already been retarded in many children with severe chronic asthma before corticosteroids were given, it is possible that the administration of these agents was responsible for further retardation of growth in a few cases.

This investigation has shown that in suitably selected cases regimens of intermittent treatment with prednisolone are as effective in controlling the symptoms of chronic asthma as continuous (daily) treatment. There are some indications that side-effects are less likely to be produced by intermittent than by continuous administration of prednisolone, but further studies will be required to confirm this tentative conclusion.

We must express our gratitude to the following physicians who were members of the staff at the asthma clinic for various periods during the past 12 years and whose careful recording of data greatly assisted the preparation of this report: Dr. A. R. Somner, Dr. A. C. Douglas, Dr. W. D. Murray, Dr. B. H. R. Stack, Dr. A. K. Zealley, and Dr. B. J. S. Hartnett. Our thanks are also due to Miss Thea Sanders and Miss Linda Tully for technical assistance ; to Mrs. Rosemary Baxter and Miss Joyce Holywell for help in the production of the manuscript; and to Dr. W. P. U. Kennedy for much useful criticism.

\section{REFERENCES}

Harter, J. G., Reddy, W. J., and Thorn, G. W. (1963). New Engl. F. Med., 269, 591 .

Livingstone, J. L., and Davies, J. P. (1961). Lancet, 1, 1310

Medical Research Council (1956). Ibid., 2, 798.

Pearson, R. S. B., Baylis, J. H., and Smellie, H. C. (1961). Brit. med. F., 1, 315 .

Phear, D., Ball, K., and Page, F. (1960). Lancet, 1, 139.

Rees, H. A., and Williams, D. A. (1962). Brit. med. Y., 1, 1575.

Somner, A. R., Rogan, M. C., and Grant, I. W. B. (1960).' Ibid., 1, 1092.

\title{
Comparison of Mortality Rates in Elderly Hypertensive and Normotensive Hemiplegic Patients
}

\author{
J. D. MERRETT,* B.SC., PH.D. ; G. F. ADAMS, † M.D., F.R.C.P.
}

Brit. med. F., 1966, 2, 802-805

Some indications for antihypertensive treatment are categorical at any age (Rosenheim, 1962), but caution is necessary in attempts to lower blood-pressure in elderly hypertensive patients, especially if they have had transient ischaemic episodes or strokes. However, strict control of blood-pressure levels, by means of hypotensive drugs if necessary, has been recommended in the hypertensive hemiplegic on the grounds that hypertension considerably reduces the chances of survival in a patient with cerebrovascular disease (Marshall, 1963). Marshall (1964) believed that the risk of reactions to long-term hypotensive therapy was not to be compared with the risk of leaving hypertension untreated in patients with non-embolic cerebral infarction. Carter (1963, 1964) also experienced higher long-term mortality rates in hypertensive than in normotensive patients, and recommended lowering raised pressure in hypertensive hemiplegics because, besides the risks of cardiac, renal, or further cerebral complications, hypertension " accelerates the advance of atherosclerotic lesions in blood-vessels and drives the process into smaller vessels." Marshall's conclusions were drawn from a threeyear review of progress in 39 patients receiving hypotensive therapy and 42 untreated patients, Carter's from a fiveyear follow-up of 178 hypertensive hemiplegics. Diastolic pressure of $110 \mathrm{~mm}$. $\mathrm{Hg}$ and over was regarded as hypertensive by Marshall and Kaeser (1961) ; Carter's (1963) criteria were systolic greater than $200 \mathrm{~mm}$. $\mathrm{Hg}$ and diastolic over 110 $\mathrm{mm}$. $\mathrm{Hg}$.

Since 1948 a series of 710 hemiplegics have been reviewed from time to time in Wakehurst House. Most of these patients

* Department of Medical Statistics, Queen's University, Belfast. t Physician, Wakehurst House, Belfast City Hospital. had cerebral thromboses-that is, non-embolic cerebral infarction. Age and sex distribution and results of treatment have been described elsewhere (Adams and Merrett, 1961 ; Adams, 1965), but the influence of blood-pressure on survival was not considered in the earlier statistical analysis because the casual pressures recorded did not conform strictly to a recognized standard method. However, by January 1965 there were only six male and 26 female survivors, and our systematic routine pressure recordings seemed to be at least as reliable as some of those used to condemn hypertension as an adverse factor in the prognosis of strokes. This paper is a study of mortality rates compiled for groups of male and female patients defined according to certain blood-pressure levels.

\section{Methods}

Elsewhere (Adams, 1965) it has been shown that pressure tends to be high at the onset of a cerebral vascular accident, falling gradually over the next eight weeks in those who survive, and then rising a little again. We have therefore limited this analysis to patients admitted or transferred to Wakehurst House not later than one month after the onset of their strokes; this accounted for 207 omissions from the analysis. Twelve patients were untraced, and 26 others with embolic cerebral infarction related to rheumatic heart disease are excluded, leaving 465 patients ( 211 men and 254 women). Survival has been estimated in months from the date of onset of the stroke until death, or until 1 January 1965.

Most of the patients were transferred from general medical wards in the third or fourth week of convalescence after surviving the onset of their strokes (Adams and Merrett, 1961). 